\title{
J
}

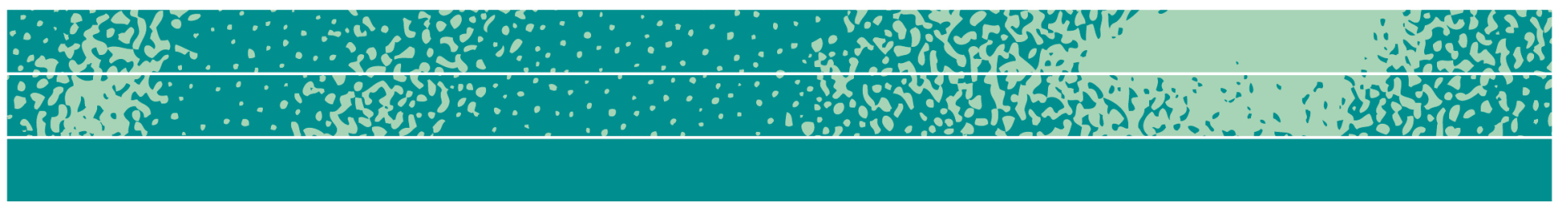

\section{An Uneasy Truce: Navigating Interdisciplinary Collaboration in the Software Industry}

\author{
Natalie D. Hanson
}

\begin{abstract}
Over the past few decades, much has been written about the ways in which project teams bring technologies to market. In this context, social scientists typically partner with specialized designers to bring their research and new concepts to life in a way that is consumable by a variety of team members, including engineers and data scientists. This paper explores one such collaboration, and describes the challenging conditions that team members face - both in their work context and with their peers - in imagining and building a commercially viable software product.
\end{abstract}

\section{Keywords}

design, collaboration, teamwork, software development, interdisciplinary

\section{Introduction}

How can researchers and designers inject humanity into the work when the vast majority of the team is technical, and the complexity of innovative new technologies is all-consuming for them? This case study
Page 1 of 26

JBA 7(2): 184-209

Autumn 2018

(C) The Author(s) 2018 ISSN 2245-4217

www.cbs.dk/jba 
focuses on the challenges of working across disciplinary boundaries, in the case when very deep sophistication is required in each discipline in order to execute, but there is not necessarily the desire to understand and fully engage across disciplinary boundaries.

Before digging into the story, however, it is important to provide some context, as the software industry is a context with different roles, processes, pressures, and a discourse that shapes the interactions of those working in this space.

The high tech industry - both hardware and software - is characterized by change. The past fifteen years has seen a shift from Waterfall to Agile software development methods, a growing focus on mobile, a shift from on-premise to cloud computing, excitement around responsive design, and much more. In fact, there are so many of these transitions to be weathered that the analyst firm Gartner issues an annual Hype Cycle report, indicating which technologies show commercial promise or are approaching mainstream acceptance and use. Gartner seeks to educate decision-makers, and ultimately informs corporate investments in this rapidly evolving technology ecosystem.

Today there are a number of factors that characterize work in the software industry - (1) unique roles, including specialized research and design skills; (2) Agile ways of working that challenge traditional engagement models; and (3) a singular focus on innovation. In addition, emergent capabilities such as (4) big data combined with artificial intelligence require teams to adapt their ways of working in order to be effective. These themes form the backdrop for the case study. They are summarized briefly below.

\section{Unique Roles}

For those teams engaged in imagining, designing and building software, there are a number of different design roles. An Experience Designer might be responsible for working with a researcher to evaluate what kind of technology solution makes sense in the context of the life of that consumer or patient. An Interaction Designer might work with an Information Architect to create appropriate navigation and compelling, usable designs for that solution. Finally, a Visual Designer would ultimately be focused on ensuring the solution is visually compelling, polished, and aligned with the brand.

Typically, the most experienced User Experience professionals work on the early, messy solution definition. Once a certain amount of clarity has been achieved, work is transitioned to an interaction designer. Although visual designers can be experienced and incredibly talented in the advertising or print space, in the software industry these types of designers often have a junior or subordinate role because they don't 
typically have training in understanding people or human-centered design methods.

Depending on the nature of the work or the composition of the team or the skills available for a particular engagement, a researcher in the software industry might have a background in anthropology or sociology, cognitive psychology, human factors engineering, humancomputer interaction, or simply in design.

In small teams these activities may be done by the same few people, whose responsibilities shift as the product gets closer to market. This combination of skills (both research and design) is often simply referred to as User Experience (UX). However, the actual skills available within any given team may vary significantly depending on training, experience, the size and maturity of the team, and of course the broader organization's culture and goals.

Due to staffing gaps (and perhaps also due to a lack of appreciation of formal research training), there are a number of new roles emerging which emphasize the role of design at the expense of research. Historically, UX skills have ranged from formal research to interaction design to front-end development. Some designers would gravitate towards a deeper understanding of technology, and others would gravitate to wanting to understand people. The composition of each team could vary for a variety of reasons.

However, recent years have seen the emergence of two new roles - Design Researcher and Product Designer. A Design Researcher likely has their primary training in a design school or program, with some focus on research methods. This is in contrast to a researcher who might have studied human factors engineering or anthropology at a school specializing in those topics. The Product Designer (a combination of Product Manager and Designer) is the design field's response to 'getting a seat at the table'. In this type of role, the designer begins to assume more strategic responsibilities such as those of a product manager. There are significant benefits, of course, to having someone with a user-centered mindset taking more responsibility for product direction. However, the focus on business topics inevitably diminishes the time and capacity for the hands-on work of user-centered design.

These roles seem to emerge for a few reasons. The first is that UX professionals want to play a more strategic role in the products they are working on. Second, the numerous roles in these teams lead to a lot of coordination. Merging roles means fewer touchpoints, less complexity, and likely more speed for all involved. Finally, the impossible gap (in the millions) between current demand and available, qualified design talent requires the streamlining of design work and staffing. Given how few team members are truly focused on the end-users in the first place, the collapsing of roles between research and design or between product 
management and design is a further compromise to staffing ratios and a focus on end-users. In addition, specialized research skills become even less of a priority, in favor of design. Business decision-makers currently have a deeper understanding and appreciation of design than of research specialties, due in part to the visibility of design-led innovation in the popular press.

\section{Agile}

Historically, software development teams worked in a method we now call Waterfall. That is, the business case and requirements cascaded down from senior management, with each team contributing their piece before handing it off to the next. It was slow, and, like the game of telephone, a lot was lost in translation by the time the product was ready to ship.

Agile software development methods were introduced in 2001 through the Agile Manifesto. ${ }^{1}$ In Agile, teams avoid handoffs through being co-located, collaborating closely, and iterating until the desired outcome is achieved or an acceptable compromise is reached. The commitment to Agile shapes the work culture and practices in many ways, it informs roles and relationships, power dynamics, rituals, and more. For more on this, see my chapter in the Handbook of Business Anthropology (Hanson, 2014).

There are some aspects of Agile that have common ground with user experience research methods. Of particular note is the commitment to get out of the building (GOOB) regularly to validate ideas. However, the urgency, immediacy, and short cycles that characterize Agile can make it challenging for a researcher to address research questions in sufficient depth; both researchers and designers must adapt how they work, especially once the regular work cadence of the engineers is established and underway.

\section{Innovation Discourse}

In the simplest terms, innovation is sought because there is the belief that a great idea or product or service is going to make a lot of money, quickly.

In Karen Ho's research about Wall Street, she describes shifts in the capitalist system, and what happens as companies become valued as assets in a portfolio, intended to be extracted for shareholder value. This abstraction serves Wall Street well; the focus is on quarterly profits rather than long-term prosperity of the business and its employees. However, that shift has significant implications. For example, the average lifespan of a corporation now is 15 years where it was 75 years in the past

${ }^{1} \mathrm{http}: / /$ agilemanifesto.org/ 
(Ho 2009, 2016). And so this sense of urgency and speed, and the desire to 'fail fast' is permeating not just technology companies, but other industries as well.

There are many conflicting opinions about whether venture capital is profitable or not. Some estimates suggest $75-90 \%$ of venturecapital backed firms are not profitable, but that those that are profitable make up for the rest. Related to this is the idea of 'first-mover advantage'; technology teams need to get their product to market first to define the market, capture the user base and grow rapidly before competition is present, and/or to provide the highest possible chance for acquisition (if that is their objective). However, whether venture capital is profitable and first mover advantage is real is almost irrelevant here; the perception of the need for urgency shapes both the discourse and the work practices in the software industry:

"People with different lifestyles and different backgrounds challenge each other more. Diversity creates dissent, and you need that. Without it, you're not going to get any deep inquiry or breakthroughs." Paul Block, CEO (Hunt et al, 2015)

There is a growing body of research confirming that innovation works best with diversity of all kinds - of thought / education, of worldview, of race, gender, and of life circumstances. However, for the most part, that is not the current reality in tech today, where white males predominate.

This research on the importance of diverse teams is slowly making its way into the business setting. The shift from STEM (Science, Technology, Engineering, and Math) to STEAM 2 (Science, Technology, Engineering, Arts and Math) is still grounded in innovation discourse, but inclusion of the Arts brings new points of view to bear on technology problems. However, if STEM education does not change to entice more women, more people of color, and/or individuals from a variety of socioeconomic circumstances, the evolutions of the software industry will be constrained by the limited set of perspectives that shape it today. As evidenced by numerous articles in the popular press - from \#gamergate (Hathaway 2017) to sexual harassment at Uber (Fowler 2017) - the industry itself needs to be more welcoming of women and diversity more generally before STEM education and jobs become desirable for a broader audience.

Yet, the fact remains that diverse teams deliver more innovative outcomes. It may well be that designers and anthropologists bring new ideas and ways of working precisely because they are different, and those differences extend beyond their disciplinary training. If the research findings themselves do not drive change either because they are not

2 http://stemtosteam.org/ 
convincing enough or not directionally correct for whatever reason, we may not be able to bring our findings to life. In these teams, our value may be in representing other ways of looking at the world. However, the act of providing exposure to and visibility into another point of view still helps to drive change and ultimately, innovation.

\section{Big Data and Artificial Intelligence}

In the technology industry today, another relatively recent theme is the focus on 'big data', and the artificial intelligence needed to harness its potential.

Some of what is being written at the moment describes the dangers of artificial intelligence (AI), and the ways it can obscure or distort how decisions get made. For example, Cathy O'Neil's book Weapons of Math Destruction: How Big Data Increases Inequality and Threatens Democracy and Virginia Eubanks' new book Automating Inequality: How High-Tech Tools Profile, Police, and Punish the Poor each provide specific and compelling accounts of the ways in which algorithms are reinforcing discrimination of all kinds, and ultimately increasing the digital divide. These concerns have been fueled by mass media reporting about Russia paying for divisive ads on Facebook (Timberg 2017, Shapiro 2017), and the ensuing impact on the most recent U.S. presidential election.

As big data came into popular understanding through the media, qualitative social scientists initially expressed concern about how it might impact the work of ethnographers in the future. Quickly, however, the tenor of those conversations has changed; there was a realization that we have always worked with qualitative data. Now, we have the opportunity not only to study its production, consumption, and use, but also to use it ourselves. It is increasingly important to ground our concerns in specific industries, specific examples, and the behaviors within project teams. These technologies are not going away; the more quickly we can stop criticizing them from afar, the sooner we can move towards an understanding of and contribution to this new reality in an ethical, informed, and impactful way.

Elish and Boyd (2017:664) remind us that "the currents of hope and fear often obscure the more nuanced and subtle shifts that are underway". The dialogue within the social sciences has become much more thoughtful and pragmatic about how to operate in relation to this emerging technology. Churchill (2017) urges us to use an ethnographic lens to "make sense of what's intentionally and artifactually collected from people's interactions with digital devices and services", and Ken Anderson and his co-authors (2017) remind us of the benefits of bringing multiple methods together. Finally, in her popular TED talk, sociologist Tricia Wang (2017) reminds us that business conditions change so fast 
that they are difficult to model effectively or exclusively with quantitative data; this opens up significant opportunities for impactful qualitative research.

Rather than making general statements about the social impact of artificial intelligence, the goal of this paper is to get specific. What are the industry drivers, the business opportunities, and where does the sense of urgency come from? Why is there a desire to harness this growing body of data, and why does that require artificial intelligence? This paper will provide some visibility into how one project team was constructed, for what purpose, and the challenges they faced in delivering valuable and human-centered outcomes against this complex backdrop.

\section{Literature Review}

Given the importance of innovation and the new in the capitalist system, it is not surprising that a plethora of books have been written on innovation; a search on 'business innovation' on Amazon returns more than forty-thousand recommendations. This includes the classic Diffusion of Innovations (Rogers 1962, 2003), Change Masters: Innovation \& Entrepreneurship in the American Corporation (Kanter Moss 1983), The Innovator's Dilemma (Christensen 1997), and textbooks like Managing Strategic Innovation and Change (Tushman \& Anderson 1997). Many of these seem to focus at a macro or executive level on creating the right conditions for change in the work context; few address what individual teams or team members can do.

Since the dot-com crash in the early 1990s, momentum has been growing in popular management and technology literature about focusing on the customer. This has been a gradual shift away from building technology for technology's sake, and recognizing the need to consider the needs of customers early in the lifecycle of building a product, service, or solution. In many ways, Roger Martin's Design of Business: Why Design Thinking is the Next Competitive Advantage (2009) led the way, fueled in part by articles about IDEO[define] and Design Thinking in the popular press. The growing interest in design thinking was intertwined with the momentum around Agile and the need for customer-centric product development. Books such as The Lean Startup (Ries 2011), Lean UX (Gothelf 2013, 2016), The Four Steps to the Epiphany (Blank 2007), and Customers Included (Hurst and Terry 2013), all seek to address creating something new under ambiguous conditions. Much of this material asserts a point of view and provides methodological frameworks. However, it is worth noting that many of the classic books on Agile and the Scaled Agile Framework (SAFe) intended for large enterprises still only mention the UX discipline in passing. In Leffingwell's more than fivehundred page book on Agile Software Requirements, which is written for a technical audience, there are less than three pages dedicated to front-end 
development (2011: 129-131) and no substantive acknowledgement of UX research or design.

In contrast, the Participatory Design tradition emerged from Scandinavia in the 1970s and made its way to the United States in the early 1990s (Schuyler and Namioka 1993:xi). Thus, collaboration across disciplines has been the subject of discussion in anthropology and design fields in the U.S. for nearly thirty years. One of the key tenets of this seminal work was to ensure that people who would ultimately engage with new processes and tools were part of the process to design them; in Norway this was called 'industrial democracy' (Ehn 1993: 48). In that early work, for example "Ethnographic Field Methods and Their Relation to Design" (Blomberg 1993: 123-155), understanding and design are described as two separate steps. The focus is on ethnographic methods and the article emphasizes the ways in which designers can learn from researchers.

More recently there has been a focus on creating a unified team, for example Reconfiguring the Social Scientist: Shifting From Telling Designers What to Do to Getting More Involved (Rogers 1997). Rogers argues that social scientists have historically attempted to impose their ways of working on other fields such as engineering and design, and that this approach shows a "lack of appreciation" (1997: 58) for the skills and complexity inherent in those other disciplines. Rogers concludes that social scientists have an important role to play as "facilitators" in helping both users and designers "reconfigure their working practices". Similarly, Miller (2016) and Favret-Saada (1990, referenced in McCabe, 2017) recommend that anthropologists can serve as brokers, either as an explicit member of the team or outside of it; we are uniquely qualified because we see dimensions of culture across those disciplines.

While compelling in some respects, these conclusions reflect an ideal state that is not grounded in the practical reality of how industry software teams are composed today. Typical teams are led by a product owner; a researcher will have a role to play, but not a central one in shaping the work practices of the project team or the ultimate end-user. Perhaps such a configuration is more realistic in an R\&D or academic or even an applied anthropology context, where the addition of advisory resources is financially viable, pragmatic, or even expected. However, in my experience in industry, designers are integrated in product teams and (in order to maximize the ebb and flow of their work) researchers work across teams. Thus, the researcher is not the authority, nor do they provide continuity throughout the product lifecycle; in the software industry outside of $\mathrm{R} \& \mathrm{D}$, that role is more likely played by the designer. In an ideal case, the designer will have deeply internalized both research findings and key aspects of relevant human behavior, as the researcher will likely be on the periphery of the team, due to their obligations across multiple products. 
A review of the literature by Choi \& Pak (2006) shows a growing consistency in the terminology used to describe team composition. Multidisciplinary teams work side-by-side, sharing knowledge but working independently. Interdisciplinary teams establish "a new level of discourse and integration of knowledge". Finally, transdisciplinary teams are "recombinant" (2006:357) transcending disciplinary boundaries to approach problems together in new ways. These ways of describing collaboration along a continuum have made their way into the field of anthropology. Miller (2016:45) articulates that "recognizing and accepting the validity of different knowledge cultures" is a critical success factor, thus signaling a shift from individual expert to collaborator. In the introduction to her book on collaborative ethnography, McCabe uses terms like 'recombinant knowledge' and 'cognitive convergence' (2017:2) which hint at the fantastic outcomes that occur when teams work together effectively. Since the inception of the anthrodesign listserv in 2002 there have been a growing number of books written about the collaboration between anthropology and design (Hanson, 2017), and the EPIC conference ${ }^{3}$ has also resulted in a wealth of new content along these lines from a variety of related disciplines.

However, with the exception of research in the field of Computer Supported Collaborative Work (CSCW), it is unclear that ideas about the value and potential of interdisciplinarity is as widespread in engineering as it has been in the applied social sciences and design. What happens when members of a team have different understandings and desires about the level of collaboration that their shared assignment require? Based on more than thirty years of grounding in participatory design concepts, user experience teams may be seeking a deeply integrated, transdisciplinary experience. In contrast, technical teams may be content with a multidisciplinary approach - a more insular or siloed engagement. In a very practical sense, these varied expectations result in a gap - or in some cases a gulf - between the aspirations and expectations of the UX team and those of their technical colleagues. For example, UX team members would like their technical teammates to be curious about research findings, and demonstrate that interest by listening in on usability testing sessions or findings read-outs. Many user experience professionals find themselves disappointed when their desire for mutual understanding and deeper collaboration across disciplinary boundaries is not shared by all team members.

As Sawyer describes in his book Group Genius, most of the literature does not appear to break open that black box of collaboration (2007: 15). How does it happen or fail to happen? Here we are not looking at an institutional level, but rather at the level of daily interactions between team members, especially across disciplines. What

\footnotetext{
${ }^{3} \mathrm{http}: / /$ www.epiconference.com
} 
can we learn from those situations? Ultimately, what is missing in the literature is a detailed view into the conditions that these teams struggle through. Thus, the purpose of this case study is to share the hard reality of collaboration in commercial software development today. What happens when a team has to deliver, in spite of not having moved through the 'storming' (Tuckman, 1997) stage? What happens when the social scientists and designers in the team desire a deeper collaboration, but the same is not true of counterparts in other disciplines? It is messy, uncomfortable, uneven, and may remain unresolved. Sometimes (usually because team members are passionate about the work or they see its potential impact on their careers) outcomes are achieved in spite of all that, at a personal cost for those most invested in achieving humancentered outcomes.

\section{Case Study}

\section{Overview}

As a project team, the initial goal was to build a 'proof-of-concept' (POC) to showcase representative features and technologies of a potential new software product. With some success, the team would secure funding for a longer term effort; the goal was ultimately to build licensable software that the company could sell to and configure for clients. The project brought together a small group of experts to conduct a POC for both the experience and the technologies. The team faced significant pressure to show value and impact during the POC, so they could receive support and funding to continue their work. This paper describes a nine-month period beginning with UX research activities in January and ends with a formal request for funding in August.

The team was comprised of sub-teams from UX, business (domain experts), technology, and data science. Working in a program management model, each functional area was responsible for a workstream, with at least one functional area in a supporting role. For example, during the user experience research and design work, the primary point of collaboration was with the business workstream. The business team was responsible for identifying relevant and compelling content. In turn, they worked in close collaboration with the data scientists, who identified existing and emerging data sources and began to craft relevant algorithms. For each sub-team, there were also partnerlevel executives in an oversight role and two to five additional team members to execute the project.

While the effort was well-sponsored and the business problem was compelling, the team faced numerous challenges in working across disciplinary boundaries, including basic issues of geographic and time zone separation (with team members in central India, San Francisco, and Chicago), an understanding of the other team members' working style, 
and how to build on other team members' deliverables. Not surprisingly, the first milestones transpired while the team was still in the 'storming' (Tuckman 1977) phase.

\section{The Business Problem}

The project team was tasked with producing software for pharmaceutical sales representatives or 'reps'. In most cases, these salespeople do not sell medicine; their role is to educate and influence physicians who are making treatment decisions. Given the choice of communication channels, physicians still prefer a sales rep to digital engagement (via email, for example). Historically, marketing in this space has been well quantified, so there is a lot of information available about what messages work, and how they work, and which doctors read or do not read email or search on the web. That provides a very data-driven foundation for approaching physicians with information about pharmaceutical products.

The idea for this solution was to select the best of these messages and data-driven insights and provide them to a rep while supplementing with compelling new data sources. However, it was challenging to deliver the information in a format streamlined enough for a sales rep, who might be touching 50, 80 or 150 physicians every few weeks. There could conceivably be hundreds of data points for a single physician; including patient data, there could be thousands of data points. In other words, this was a classic 'big data' problem.

Another critical dimension of the business problem was that very seasoned sales reps believe they are good at what they do. Individuals with significant tenure in their role may not want automated suggestions intended to make them more effective; such suggestions could be seen as insulting or invasive at worst, irritating at best. Thus, the way these insights or suggestions are packaged and provided has to be done with care. UX has a critical role to play in ensuring that the content was relevant, consumable, and not alienating.

\section{Team Composition}

The project team itself was comprised mostly of engineers. Some engineers work on the back end (or the server side) of the solution, which is the complex underlying infrastructure. However, there are different technology skills required to build the front end (or interface) for that solution. Thus, many projects have at least two separate engineering teams that need to be coordinated. The front end developers (the FEDs) typically have the most interaction with researchers and designers.

More recently, as the use of big data becomes more common we see the emergence of data scientists who are responsible for imagining 
and creating the algorithms that are used to query or elicit outcomes from these large or complex datasets. The data scientist is deeply focused on the data itself, and extracting the elusive and desirable 'insights' from the raw content in a nuanced way that moves beyond simple, easily programmable business rules.

Finally, the team may have one or more researchers and/or designers, as described earlier.

In the consumer industry, a typical ratio of user experience capabilities relative to engineering would be one researcher or designer to ten engineers. In the enterprise software space (systems to manage the internal processes of large companies), 1 to 100 (or even 1 to 1000) is more common (Yen 2017). For the newest products coming to market, there is a growing understanding that a focus on design is increasingly critical to success (Maeda 2016). This matters for numerous reasons, but one of the major ones is that there is a growing body of research that shows it is difficult to achieve innovation without diversity (Rogers 2003: 271-296, Hunt 2015). As noted earlier, innovation is perceived as significant in this space. The desire to deliver a consumer-grade experience into the enterprise also requires a higher degree of UX investment and staffing.

In a project team like this one, the researchers or the designers are the ones who are asking the questions about people. Who is going to use this? What do they care about? Are we actually solving the right problem? Is this technology the way to solve that problem? If we have already built a prototype, how does the user feel about it? How do they interact with it? For the most part, the questions about making the solution usable, compelling, and ultimately desirable for people come from the researchers or the designers, who typically represent $10 \%$ or less of the overall team staffing.

\section{Getting to Work}

The POC was intended to create new market opportunities by upgrading an existing product concept. The team's goal was to deliver a userfriendly and differentiated experience with new technologies. What most characterized the change was (a) the commitment to deliver a consumerlike experience, including dimensions such as the interface, the degree of personalization, and the performance, and (b) a shift from simple business rules to algorithms against a much larger and more varied data set.

However, in contrast to other case studies I have read, the goal of this project was not pure Research \& Development absent market pressures, nor is the anthropologist acting as a neutral coach to broker dialogue across the team. This was realization of a technical vision with a 
desire to prove a concept and a pressing timeline to commercialize it. This case study focuses on the activities of various sub-teams during a nine-month period leading up to the formal request for funding.

In a project of such speed and complexity, there are many interactions and learnings across teams. However, in the interest of focusing on critical moments of alignment, this piece focuses on three critical moments in the project (1) the definition of target users and the key scenarios the solution would support in the first few months of the year; (2) the design of a first prototype to support usability testing in May; and (3) the creation of a demo script for a key funding milestone at the beginning of August.

Each of these milestones was marked by the creation and sharing of new boundary objects, developed by the User Experience team to create a foundation for shared understanding. The unstated objective in producing and sharing UX artifacts was to help the team shift from a multidisciplinary approach to an inter- or transdisciplinary one.

\section{Identifying Users and Key Scenarios}

There is an ideal way that technology projects are run, in which business case development and substantive user research takes place before development begins. But in my nearly 20 years of experience that rarely happens; usually there is some kind of technology evaluation or proof-ofconcept underway while the user experience team is just getting engaged. Said another way, any kind of business case or formative research has either been skipped, or is presumed to be understood. Fortunately, in this case the UX team had amassed a body of research about sales people over the course of several years. With this foundational research in hand, the UX team was able to move quickly into subsequent stages of work.

The User Experience team was engaged in January. The other workstreams were still being staffed, but in order to meet aggressive timelines, UX work began without the involvement of other workstreams. In addition to reviewing previous research, the team engaged with nearly thirty consulting teams who had also done work on salespeople. Using that information, designers began by creating empathy maps (Farnworth 2014) for various sales roles. Similar to a market segmentation exercise, an empathy map builds on personas by capturing a list of needs for a particular target group. Empathy maps can be based on primary research or with stakeholders as a hypothesis about the target group's needs. Using primary research from the past, the UX team began to create empathy maps, and quickly arrived at the conclusion that there was significant overlap in the sales roles that were being designed for. As a result, the team recommended a single, common experience across roles (with different data) to the project sponsor. 
As the team gradually formed, the UX team described the different types of sales reps to the project team through some simple, researchbased user types. ${ }^{4}$ The UX team guided a discussion about the different types of sales reps, and what the day in the life of a primary care rep (who might focus on broad issues like cardiology or diabetes) might look like. The UX team made clear that those primary care sales reps have a very different pattern of work than a specialty rep, who might have access to very different kinds of data, have a much physically larger territory (therefore spending more time in the car), call on fewer physicians, and be able to schedule (and keep) regular appointments with physicians. These reps must also be deeply knowledgeable in a disease area in order to be seen as credible to a healthcare practitioner. In conjunction with the project sponsor and team, we agreed that the strongest starting point (the Minimum Viable Product, or MVP) would be with a classic retail (or primary care) rep, since there is more data (and more consistent data) to work with. The team recognized that there would be additional challenges for the data science team against the less robust data sets that characterize specialty pharmaceuticals.

By culling prior research and reviewing the work of many other project teams, the UX team began to construct a journey map that described key moments in a rep's typical pattern of work (monthly, weekly, daily). The lowest points on that journey map were identified, and this deeply informed UX recommendations about what the product should seek to support and enable. In other words, the findings supported the prioritization of certain solution features and capabilities. This understanding in turn allowed the UX team to make some high-level recommendations about which types of data or insights might be the most useful in the context of this particular type of rep's workday. During this process, the UX team also sought guidance from the business workstream team members about what types of data would be the most impactful at that moment.

At the conclusion of the discovery research and synthesis effort, the UX team had a clear understanding of the similarities and differences between the types of users under discussion, and an understanding of what kinds of scenarios the users traversed throughout their day. Perhaps most importantly, the team had identified four major points in the day that could be addressed by the technology under discussion.

However, the UX team members grossly underestimated how much they had learned as a team during that discovery phase. They were working together largely out of the Midwestern United States, with some support from the East coast. In hindsight, there should have been more thoughtful and clear decisions about how the other workstreams engaged

\footnotetext{
${ }^{4}$ In this case, we did not create personas, but rather focused on the differences by job function. We felt that the subtle distinctions that personas would evoke were not as relevant in this case, nor did we have time to create superfluous artifacts.
} 
in the process and outcomes during that two to three month period. As UX began the knowledge transfer, many of the conclusions and insights that the UX team took for granted needed to be reviewed in detail and justified. Significant time and effort was spent on ensuring other team members were on the same page.

Scenarios and pain points were articulated to other members of the project team through concise deliverables shared over a series of conference calls, but it was not necessarily as clear why those scenarios were represented the way they were, or why certain scenarios had not been chosen. There were nuances in what had been selected that were only evident to team members who had participated in the discovery and synthesis from the beginning. In other words, only the UX team. This would lead to issues later in the project; months later as the full team sought deeper understanding and engagement with this early content, gaps in the scenarios were identified that put the entire design concept at risk.

\section{Prototype for Usability Testing}

As the UX discovery period came to a close, the designer began to create screens in preparation for usability testing. These were not simple wireframes. Rather, the testing required an interactive prototype with some representative content. However, as the members of the business workstream were getting up to speed, the UX team was required to use their own judgement and experience to create that content. They would learn later that they had missed the mark on the content in subtle ways. This was not critical for usability testing, but it did result in some tough stakeholder feedback and rework later in the project.

The usability testing went very well - not just feedback on the new concept and experience, but in terms of detailed usability testing of the solution; the users were able to both understand the concept and complete the tasks for which it was designed. Needless to say, the UX team came out of the research elated; they wanted to transmit the findings to the team at large to ensure that everyone was clear about the most important aspects of that design. The hope was to ensure the project team as a whole retained an appreciation of the design rationale, even as the team continued to grow. The usability testing findings were shared in a series of meetings across time zones to make sure the whole team was exposed to what was discovered.

However, in my experience, methodology and findings are always less important (not just to executives but to team members) than the implications for their own work. Rather than truly focusing on the user point of view and what was learned in the testing, each project team member listens and filters with a focus on whether and where they have to make adjustments in their own work. As such, there was a follow up 
meeting with the technical team in particular to articulate how this new experience would have to evolve in response to what was discovered in the usability testing. In addition to the research findings, a series of slides was developed that described what was learned and what it meant for the solution, as well as a set of updated designs that documented the subtle but nonetheless important changes. That documentation was used to begin updates to both the UX prototype and the associated demo script.

\section{Demo Script}

As part of building the interactive prototype for usability testing, it was necessary for the User Experience team to string scenarios and some representative content into a demo script. The UX team was not deeply concerned about the details of the content for usability testing, because the initial focus was on navigation and general usability of the key interactions. However, there were a number of synergies between the materials needed for usability testing and the demo script. Thus, the goal was to create a single script that could be used for usability testing, and then later to showcase the solution capabilities to the business sponsor and ultimately to our clients.

The UX team used a storyboard format to bring the rest of the team along on the storyline for both the usability testing and the demo script. In order to ensure continued progress, the UX team enabled the business team with a spreadsheet to provide sample data back for the screens. By gently reinforcing the scope and approach with their own artifacts (or boundary objects), the UX team hoped to guide the approach of the group to a more user-centered, focused, and experience-friendly outcome.

However, as the initiative gained momentum, the team expanded. For reasons that remain unclear, new team members created a second demo script which didn't leverage the earlier scenarios defined by UX, and which didn't provide UX the content necessary to create polished screens. The business team also created the initial script for a concept video. However, the three scripts (UX demo, business demo, and video) were each slightly different, necessitating three different sets of screens. While the team was able to achieve some degree of alignment across them all, key dates (e.g. recording of the video) required that all workstreams forfeit consistency for speed of execution.

On one hand, all the team members were thrilled to see the growing momentum. On the other hand, this late-breaking news meant additional work and urgent need for better coordination across teams. For the UX team, it meant being aware of, reviewing, monitoring, and providing feedback on a fourth set of screens. At the breaking point, the team requested that one of the four main deliverables should have primacy. The UX prototype (while the most current and in line with 
usability testing findings) was abandoned in favor of focusing on the technical POC. For the remaining weeks, the business effort went into refining the content for a subset of POC screens, and UX effort went into auditing the technical work, and ensuring that the screens were being built as designed.

\section{Getting it Done}

As the momentum grew, many of the questions that emerged from senior stakeholders were around technical capabilities and feasibility. It became increasingly clear to the sponsor that a full technical proof-of-concept would be required to ensure a successful request for funding. Thus, a mere eight weeks before the funding milestone meeting, the technical team began to build a technical proof-of-concept.

During those last eight weeks, the UX team found a number of cases where the technical team had taken liberties with the design concept. When they began asking the technical and data team to reconsider their choices, they felt the first major points of resistance. The technical team tried to explain that the algorithms would address the overwhelming volume of data, much in the way that algorithms on Facebook present only $20 \%$ of the available content to its users (Rader \& Gray 2015), using over one hundred thousand algorithms (Page 2016). The UX team tried to explain that the system would fail if it was not designed in a way that was aligned with human behavior - it did not matter what data was there. In the end, the team achieved an uneasy truce, agreeing on the key themes (e.g. recency) that would drive the algorithm, but not working deeply together on the specifics. Both sides recognized that only a client implementation with real datasets would reveal the appropriate level of filtering that would be necessary for a compelling, consumer-grade experience.

Original design concepts were also being challenged as the build got underway in earnest. For example, the front-end developers had enabled swiping to remove a newsfeed item. This is a good interaction for a mailbox, but not an appropriate paradigm for a newsfeed. Thus, what appeared to the front-end developers as an innovation appeared to the UX team to break the underlying mental model of the design.

Consequently, each feature - and even each interaction within that feature - required (re)discovery, clarification on design rationale, and occasionally the revisiting of decision-making authority. The move from UX prototype to technical POC did not mean that UX was no longer responsible for the design, but in fact it became increasingly difficult to retain control of the design concept and its execution in code as the center of gravity for the project shifted from the U.S. to India. 
These three critical moments in the project (agreement on the target users, finalization of the prototype for usability testing, and creation of a demo script) were each difficult in their own way. Some of those challenges had to do with the construction of the team working remotely, across time zones and cultures. Many of the challenges had to do with less obvious issues, such as the ability to communicate, empathize, and align across disciplinary boundaries. However, in spite of the various challenges they faced, the team did secure funding to continue their efforts. This resulted in a more ambitious set of goals for the subsequent twelve to eighteen months. As is often the case in the software industry, the size of the UX team remained the same while many new technical team members were added to bring the concept to life, and ultimately to market.

\section{Discussion}

What have we learned from this case study about interdisciplinary collaboration in the software industry? In many ways, I feel that it points to a disconnect in the academic literature on this topic in at least three ways: (1) time pressures play a significant role in shaping interactions and work practices, (2) complexity of team structure makes collaboration across disciplinary boundaries difficult, and (3) anthropologists are not present - as brokers or otherwise - in such contexts. We'll take each of these in turn, below.

\section{Time Pressures}

The backdrop of Agile shapes work practices and the resulting boundary objects, but it is perhaps a less critical factor in this case than the time pressures. The reality of urgent timelines, commercially-focused, globally distributed teamwork, and collaboration across disciplines has also been made evident. The urgency to get started resulted in the staggered arrival of key project team members. This created challenges both in project delivery and in establishing any meaningful sense of team, as did the distributed nature of the group. Co-location is supposed to be a requirement for Agile software development teams. More than any other factor, co-location (or even a larger overlap in time zones) would likely have accelerated shared understanding and alignment or 'norming' (Tuckman 1977). However, cost pressures resulted in staffing the entire technical team in India, which made true integrated, Agile iteration and delivery a challenge.

\section{Complexity of Team Structure}

There is classic Venn diagram from IDEO and the Stanford d.school 
(Schmiedgen, 2013:22) which describes Design Thinking as having three key dimensions - technology feasibility, business viability, and human values (usability, desirability). Good design, an optimal user experience, and ultimately innovation happen where those three dimensions overlap at the center of the Venn. Historically, this diagram was also an effective way to describe the composition of a project team. Engineers were primarily concerned for technology, product managers and business analysts for the business viability, and the user experience team for the human aspects. In a high functioning team, the center of the Venn (the keyman) is a shared responsibility.

In this project, the addition of the data science team added a fourth circle to the Venn. This dimension of coordination had not existed in the past, and it was new for almost all team members. For example, for the business workstream, the primary points of integration were with UX on one hand (as it regarded the overall experience and scenarios), and with data scientists, on the other. Data scientists worked with the technology and business teams, but had little interaction with UX. In turn, the majority of UX interaction was with the business team, and later with the technology team. There was little to no direct interaction with the data scientists.

In this team structure, the number of different teams and the complexity of coordination led to a number of challenges, in spite of good intentions:

- The UX discovery process had identified potentially new data sources that had not been explored in the past. The business team's challenge was to create a robust framework for this larger set of data. This required close collaboration with the data science team to identify the data sources and how to acquire them, understand the structure of those sources, and determine (with the tech team) how those would be ingested and integrated into the system. Ultimately, the team needed to arrive at a shared understanding about how these new sources would be filtered and presented in the experience (or content container) being created by the UX team. This required the UX team to understand the data deeply enough to create a set of design standards for each potential data visualization.

- The technical team was based in India, and they were responsible for making the recommendations regarding what components would need to be built or bought, and ensure all the pieces would fit together. In some cases the team did small technical proofs of concept (POCs) to make sure the different components worked together as expected. Due to their later start and the necessary focus on their own project 
commitments, the technical team had little to no understanding of the insights that led to the experience that was designed, beyond the user types and wireframes as an output.

- The primary responsibility of the data science team was to help make the shift from rules-based to algorithm and machine learning-based consumption of existing and new data sources. They typically have a deep understanding of tools and technologies to write algorithms, but they are not always domain experts. Thus, the collaboration with the business workstream was key. Like the technical team, the data scientists were largely based in India, had not lived or worked in the U.S., or been exposed in any significant way to the healthcare system, healthcare providers, or sales people. They joined the project after UX discovery, initial design concepts, and usability testing were complete, which effectively resulted in no exposure to the findings and recommendations by the UX team.

It becomes evident that while user experience professionals are working on a team with data scientists, with the exception of routine status calls, there is virtually no interaction between them and the designers. Thus, there is no obvious moment for the UX team to have a perspective on whatever biases or limitations might be present either in the data or in the algorithms being written. In this case, that may have been as a result of the geographic distance, or the fact that the UX team was comprised almost exclusively of interaction designers, with less interest in such topics.

However, closer collaboration between UX and data scientists does seem to have potential. While engineering teams may be seeking clarity in order to execute (e.g. a simple wireframe so that front-end code can be written), data scientists have to cope with - and ultimately make sense of - many layers of complexity to develop effective algorithms. This may make them more appreciative of a nuanced user-centered perspective than their pure engineering colleagues.

Nonetheless, given the staggered arrival of team members, the professional, geographic, cultural distance, and the pressing timeline, it is not surprising that all team members would not deeply understand the intended users of the product. Even without the significant challenge of time zone overlap, within project timelines it was not possible to expect each workstream to be deeply knowledgeable about the others.

\section{The Role of Anthropology}

It has likely become evident through this case study that — with the 
exception of my role as a narrator - anthropologists are not present at all in the narrative, nor are there any social scientists serving as brokers. Rather, designers with research skills and experience were responsible for developing an understanding of the potential users and their context of use.

The commercial part of the technology sector (as opposed to R\&D) maintains a rapid pace of change, including both new technologies and commodification of the old. Combined with globally distributed teams, this provides a culturally distinct backdrop in which to assess the value and impact of our work. Ultimately, those who wish to write in a thoughtful and impactful way about the software industry must engage with practitioners. The insider perspective is critical in order to be able to reflect in a meaningful way on both the challenges and the opportunities.

\section{Conclusion}

The intent of a boundary object as initially defined is to enable cooperation without consensus (Star 2015c: 250-51). Yet, a certain degree of shared coherence is necessary in order for that object to serve its purpose. It is perhaps obvious but important to note that a shared objective and an urgent deadline constitutes neither a team nor a community of practice. There are interesting and sometimes difficult discussions that happen from these siloed positions. In order to win the minds (and maybe even the hearts) of technical teammates, a big part of our work in the social sciences and design is to create the boundary objects and provoke discussion so that the team blends different perspectives together into the best possible outcome. Yet, the pressure facing commercially-focused teams makes it challenging to deliver one's own work and make all the necessary connections to other workstreams.

Anthropologists and designers may be emotionally invested in their work, thoughtfully crafting boundary objects with the hope of brokering understanding across the various disciplines which comprise the team. However, due to geographic and time zone separation, cultural differences, or simply lack of interest, that desire is not necessarily shared by other disciplines within the same team. As a result, boundary objects that are crafted as a labor of love to transmit a rich understanding of users are not necessarily valued, and may be reinterpreted or ignored as they moved across workstreams. This leads to confusion and rework, as well as unhappiness for those committed to a user-centered approach. Social scientists and designers may need to self-regulate as regards the emotional investment in their own work; their deep commitment to a user-centered approach may alienate other team members, or result in burning themselves out. 
In this case, only the UX team was actively seeking to achieve a deeper (interdisciplinary or transdisciplinary) level of collaboration. While the Participatory Design and CSCW traditions include technologists, a closer read on Starr's early work on boundary objects reveals that it was focused within a discipline, whether neurophysiology (2015c), zoology (Star \& Griesemer, 2015)), or artificial intelligence (2015c). Thus, we have more work ahead to truly break open that black box; understanding what it takes to cultivate true collaboration across wildly different disciplines.

\section{References}

Anderson, K.; Nafus, D.; Rattenbury, T.; Aipperspach, R. 2009. "Numbers Have Qualities too: Experiences with Ethno-Mining". Chicago, IL: EPIC Proceedings, pp. 123-140.

Blank, Steven Gary. 2007. The Four Steps to the Epiphany: Successful Strategies for Products that Win. 3rd edition.

Blomberg, Jeannette, Lucy Suchman, and Randall H, Trigg. 1997. "Reflections on a Work-Oriented Design Project" in Social Science, Technical Systems, and Cooperative Work: Beyond the Great Divide, edited by Geoffrey C. Bowker, Susan Leigh Star, William Turner, and Les Gasser, 189-215. Mahwah, NJ: Lawrence Erlbaum Associates.

Choi, Bernard C.K. and Anita W.P. Pak. 2006. "Multidisciplinarity, interdisciplinarity and transdisciplinarity in health research, service, education, and policy: 1 . Definitions, objectives, and evidence of effectiveness". Clinical and Investigative Medicine, 29(6) 351-364.

Christiansen, Clayton M. 1997. The Innovator's Dilemma. Cambridge, MA: Harvard Business School Press.

Churchill, Elizabeth. 16 September 2017. "The Ethnographic Lens: Perspectives and Opportunities for New Data Dialects" on EPIC People. https://www.epicpeople.org/ethnographic-lens/. Accessed December 2017.

Ehn, Pelle. 1993. "Scandinavian Design: On Participation and Skill" in Participatory Design: Principles and Practices, edited by Douglas Schuler and Aki Namioka. Hillsdale, NJ: Lawrence Erlbaum.

Elish, M. C. and Boyd, Danah. 2017. "Situating Methods in the Magic of Big Data and Artificial Intelligence" in Communication Monographs, forthcoming. Available at SSRN: https://ssrn.com/abstract=3040201. Accessed December 2017.

Eubanks, Virginia. 2018. Automating Inequality: How High-Tech Tools Profile, Police, and Punish the Poor. New York, NY: St. Martin's Press. 
Farnworth, Demian. 2014. "Empathy Maps: A Complete Guide to Crawling Inside Your Customer's Head" on Copyblogger.

https://www.copyblogger.com/empathy-maps/.

Fowler, Susan. 2017. "Reflecting on One Very Strange Year at Uber" on Susan Fowler's website.

https://www.susanifowler.com/blog/2017/2/19/reflecting-on-onevery-strange-year-at-uber. Accessed December 2017.

Gartner Hype Cycle Report. 2017.

https://www.gartner.com/technology/research/hype-cycles/. Accessed December 2017.

Gothelf, Jeff and Josh Seiden. 2013. Lean UX: Applying Lean Principles to Improve User Experience. Eric Ries, series editor. Cambridge, MA:

O’Reilly.

Gothelf, Jeff and Josh Seiden. 2016. Lean UX: Designing Great Products with Agile Teams. Eric Ries, series editor. Cambridge, MA: O'Reilly.

Griesemer, James R.. 2015. "Sharing Spaces, Crossing Boundaries" in Boundary Objects and Beyond: Working with Leigh Star. Cambridge, MA: The MIT Press, pp. 201-218.

Hathaway, Jay. 2017. "What Is Gamergate, and Why? An Explainer for Non-Geeks" on Gawker.com. http://gawker.com/what-is-gamergate-andwhy-an-explainer-for-non-geeks-1642909080. Accessed December 2018. Hanson, Natalie. 2014. "Recognizing Agile" in Handbook of Anthropology in Business, edited by Rita Denny and Patricia Sunderland, 540-555. New York, NY: Routledge.

Hanson, Natalie. 2017. Origins of Anthrodesign on Natalie Hanson's website. https://nataliehanson.com/2017/01/09/origins-anthrodesign/

Ho, Karen. 2009. Liquidated: An Ethnography of Wall Street. Durham, NC: Duke University Press. https://doi.org/10.1215/9780822391371

Ho, Karen. 2016. Closing Keynote, EPIC Conference. https://2016.epicpeople.org/schedule/

Hunt, Vivian, Dennis Layton, and Sara Prince. 2015. "Diversity Matters" on the McKinsey website.

https://www.mckinsey.com/ /media/McKinsey/Business\%20Functions /Organization/Our\%20Insights/Delivering\%20through\%20diversity/De livering-through-Diversity-web-final.ashx. Accessed December 2018.

Hurst, Mark and Phil Terry. 2013. Customers Included: How to Transform Products, Companies, and the World - With a Single Step. New York, NY: Creative Good.

Leffingwell, Dean. 2011. Agile Software Requirements: Lean Requirements Practices for Teams, Programs, and the Enterprise. Boston, MA: Pearson Education. 
Maeda, John. 2016-2017. Design in Tech Report. https://designintechreport.wordpress.com/. Accessed December 2017. Martin, Roger. 2009. Design of Business: Why Design Thinking is the Next Competitive Advantage. Boston, MA: Harvard Business School Publishing. McCabe, Maryann. 2017. Collaborative Ethnography in the Business Environment. New York, NY: Routledge.

Miller, Christine Z. 2016. “Towards Transdisciplinarity: Liminality and the Transitions Inherent in Pluridisciplinary Collaborative Work". Journal of Business Anthropology, Special Issue 2: 35-57.

https://doi.org/10.22439/jba.v1i1.4959

Moss Kanter, Rosabeth. 1983. Change Masters: Innovation \& Entrepreneurship in the American Corporation. New York, NY: Simon \& Schuster.

O’Neil, Cathy. 2016. Weapons of Math Destruction: How Big Data Increase Inequality and Threatens Democracy. New York, NY: Crown Publishing Group.

Rader, Emilee, and Rebecca Gray. 2015. “Understanding User Beliefs About Algorithmic Curation in the Facebook News Feed" in Proceedings of the 33rd Annual ACM Conference on Human Factors in Computing Systems, pp. 173-182.

Ries, Eric. 2011. The Lean Startup: How Today's Entrepreneurs Use Continuous Innovation to Create Radically Successful Businesses. New York: NY: Crown Business.

Rogers, Everett M.. 2003. Diffusion of Innovations, 5th edition. New York, NY: Simon \& Schuster.

Rogers, Yvonne. 1997. "Reconfiguring the Social Scientist: Shifting From Telling Designers What to Do to Getting More Involved" in Social Science, Technical Systems, and Cooperative Work: Beyond the Great Divide, edited by Geoffrey C. Bowker, Susan Leigh Star, William Turner, and Les Gasser, 57-77. Mahwah, NJ: Lawrence Erlbaum Associates.

Sawyer, Keith. 2007. Group Genius: The creative power of collaboration. New York: Basic Books.

Schmiedgen, Jan. Design Thinking - Bootcamp. https://www.slideshare.net/janschmiedgen/design-thinkingbootcamp. Accessed December 2017.

Schuler, Douglas and Aki Namioka. "Preface" in Participatory Design: Principles and Practices, edited by Douglas Schuler and Aki Namioka. Hillsdale, NJ: Lawrence Erlbaum. 
Shapiro, Leslie. 2017. "Anatomy of a Russian Facebook Ad" in the Washington Post.

https://www.washingtonpost.com/graphics/2017/business/russianads-facebook-anatomy/. Accessed December 2017.

Star, Susan Leigh. 2015a. "Revisiting Ecologies of Knowledge: Work and Politics in Science and Technology" in Boundary Objects and Beyond: Working with Leigh Star. Cambridge, MA: The MIT Press, pp. 13-46.

Star, Susan Leigh. 2015b. "The Ethnography of Infrastructure" in Boundary Objects and Beyond: Working with Leigh Star. Cambridge, MA: The MIT Press, pp. 473-488.

Star, Susan Leigh. 2015c. "The Structure of Ill-Structured Solutions: Boundary Objects and Heterogenous Distributed Problem Solving" in Boundary Objects and Beyond: Working with Leigh Star. Cambridge, MA: The MIT Press, pp. 243-259.

Star, Susan Leigh and James R. Griesemer. 2015. "Institutional Ecology, 'Translations,' and Boundary Objects: Amateurs and Professionals in Berkeley's Museum of Vertebrate Zoology, 1907-1939" in Boundary Objects and Beyond: Working with Leigh Star. Cambridge, MA: The MIT Press, pp. 171-200.

Timberg, Craig, Elizabeth Dwoskin, Adam Entous and Karoun Demirjian. 2017. "Russian Facebook ads, now publicly released, show sophistication of influence campaign" in the Chicago Tribune.

http://www.chicagotribune.com/bluesky/technology/ct-russianfacebook-ads-20171102-story.html. Accessed December 2017.

Tuckman, Bruce W. and Mary Ann C. Jensen. 1977. "Stages of SmallGroup Development Revisited" in Group \& Organization Studies 2 (4):419427.

Tushman, Michael L. and Philip Anderson. 1997. Managing Strategic Innovation and Change: A Collection of Readings. New York, NY: Oxford University Press.

Wang, Tricia. September 2017. "The Human Insights Missing from Big Data" on TED.com.

https://www.ted.com/talks/tricia wang the human insights missing fro m big data. Accessed December 2017.

Yen, Sam. June 2017. "Driving Organizational Change Through Design" at the Enterprise User Experience Conference. https://www.youtube.com/watch?v=CgsUMu-LHi0. Accessed December 2017. 
Natalie D. Hanson, Ph.D. is a Principal and partner at ZS, where she built and now leads the User Experience team across both engineering and technology consulting organizations. Prior to ZS, she worked at software giant SAP, where she also built a User Experience team supporting Board-level projects. Natalie holds an MA in Whole Systems Design from Antioch University Seattle, and a PhD in Anthropology from Temple University. She researches work practices and work environments, with a focus the ways institutions respond to macroeconomic, industry, and regional trends, and how the resulting organizational changes affect the lives of employees. Natalie is the founder of anthrodesign, a vibrant, global, online community of over three thousand multi-disciplinary researchers who use ethnographic methods in the business setting. She blogs regularly at http://www.nataliehanson.com. 